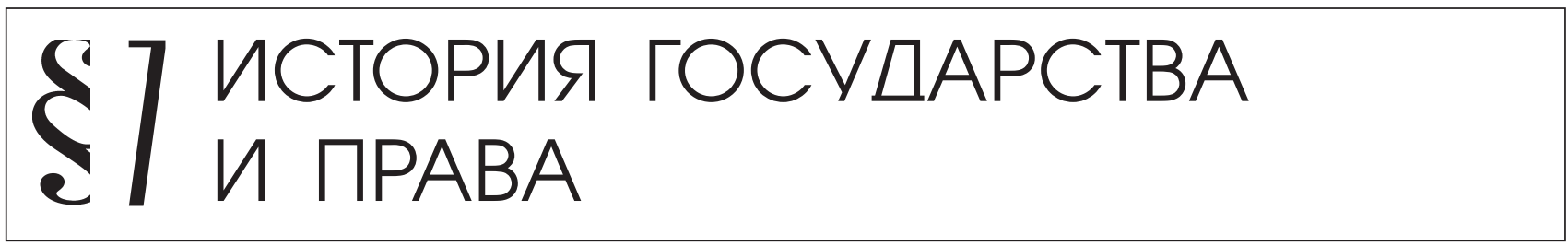

Алейников А.В

\title{
«НЕ ДОЛЖНО НИКОМУ МЕШАТЬ ЧЕСТНЫМ ОБРАЗОМ ДОСТАВАТЬ СВОЙ ХЛЕБ»: К 240-ЛЕТИЮ МАНИФЕСТА О СВОБОДЕ ПРЕДПРИНИМАТЕЛЬСТВА ЕКАТЕРИНЫ II
}

Аннотация: Объектом статьи является комплексное исследование на основе переосмысления широкого исторического материала многогранной проблемы историко-культурной специфики генезиса российского предпринимательства и разных композииии его отношений с властью.Рассматривается историко-культурная специфика генезиса производительного и деструктивного российского предпринимательства в России. На основании анализа экономических реформ Екатерины II рассматривается проблема формирования и основных параметров российской модели взаимоотношений предпринимательства и власти. Особое внимание уделяется политике Екатерины II по снятию стеснений и существенных ограничений развития частного предпринимательства со стороны органов государственного управления, отличию этой политики от предыдущих и последующих композиций отношений предпринимательства и власти, меры по усилению роли предпринимательства, государственной политики стимулирования предпринимательской активности, создания условий его развития в историко-культурном контексте соотношения формальных и неформальных правил. Принципиальная политическая установка по отношению к предпринимательству в екатерининскую эпоху- «торг-дело вольное»-реализовывалась в преобразовании многих казенных монополий, расширении правовых основ формирования частного предпринимательства. Однако, несмотря на огромное значение екатерининских преобразований, основной доминантой хозяйственной стратегии и критерием успеха предпринимательства в России осталось поглощение чужой собственности, а не ее создание и эффективное управление. В проиессе исследования были использованы основные методы исторического познания: комплексного и системного анализа предпринимательства как сложного социального феномена, единства исторического и логического в формировании предпринимательства, диалектики, противоречивости природы предпринимательства, компаративного анализа национального и глобального в формировании предпринимательства Основными выводами проведенного исследования являются показ на широком историческом материале зависимости в России любых экономических агентов от близости к власти, служение которой является главным каналом доступа к ресурсам, существенно замедляет социально-экономическое и политическое развитие общества. В результате торгово-промьшленное сословие не имело того удельного веса в обществе, которое оно могло бы иметь благодаря своей активной роли в хозяйственной жизни. Отсутствие свободной конкурениии, не связанной с откровенным аппаратно-государственным протекиионизмом, имеет свои исторические предпосылки и приводит к неоднозначным последствиям, препятствуя формированию производительного предпринимательства, которое является «сущим народным облегчением».

Ключевые слова: Россия, власть, предпринимательство, Екатерина II, государство, собственность, свобода, манифест, свобода предпринимательства, деструктивное предпринимательство.

Abstract: The object of this article is an in-depth research on the grounds of rethinking the vast historical materials on a multifaceted problem of historical and cultural specificity of the genesis of Russian entrepreneurship and various compositions of its relationship with the government. Based on the analysis of the economic reforms of Catherine the Great, the author examines the problem of establishment and main parameters of the Russian model of relationship between entrepreneurship and the government. A special attention is given to Catherine the Great's policy to remove restrictions and significant limitations on development of private entrepreneurship from government authorities; the difference between this policy and preceding and future compositions of relations between entrepreneurship and the government; measures on strengthening the role of entrepreneurship, state policy on stimulation of entrepreneurial activity, and creation of a favorable environment for its development within the historical and cultural context of the correlation of formal and informal 
DOI: $10.7256 / 1811-9018.2015 .7 .15439$

При цитировании этой статьи сноска на ооі обязательна

\section{Право и политика 7 (187) 2015}

rules. Among the main conclusions is the fact that despite the importance of Catherine the Great's reforms, the dominant business strategy and criterion for success of entrepreneurship in Russia, remained the acquisition of the businesses of others, rather than creation and effective management thereof.

Keywords: Property, state, Catherine the Great, entrepreneurship, authority, Russia, freedom, Manifesto, Freedom of entrepreneurship, destructive entrepreneurship.

$\mathrm{P}$ оссийский политический философ Александр Панарин на начальном этапе постсоветской трансформации писал, что“ "предпринимательство и народ”- главная тема российской истории; от того, как она будет раскрыта и решена, зависит все наше будущее»[1,c.198].

240 лет назад, 17 марта 1775 года, Екатериной Великой был принят Манифест « О высочайше дарованных разным сословиям милостях, по случаю заключенного мира с Оттоманскою Портою», ставший новым этапом в развитии российского предпринимательства и вошедший в историю как «Манифест о свободе предпринимательства». Суть провозглашаемых экономических свобод и ослабления государственного «конструирования» предпринимательства сформулирована в 11 статье Манифеста: « Никому ниоткуда не воспрепятствовано было свободно заводить станы разного рода и на них производить всякого рода рукоделия без других на то дозволений, или приказаний, ибо сею статьею всем и каждому дозволяется и подтверждается добровольно заводить всякие станы и рукоделия производить, не требуя на то уже иного дозволения от вышняго или нижняго места»[2,c.84].

Вот лишь некоторые итоги екатерининских мер по усилению роли предпринимательства, государственной политики стимулирования предпринимательской активности, создания условий его развития и институционального дизайна .

Если с 1630 по 1724 год число городских жителей возросло с 292 до 328 тыс. человек, то с 1724 по 1796 год увеличилось почти в четыре раза. В 1762 насчитывалось 984 фабрики и завода, а к концу царствования Екатерины II их число росло царствования Екатерины 11 составило 3161 предприятие. Снятие с торговли и промышленности регламентаций, открытие первых кредитных учреждений, развитие торгового мореплавания, учреждение заграничных консульств и заключение торговых конвенций оживило внешнюю торговлю. Экспорт увеличился с 13 млн до 57 млн руб., а импорт - с 8 млн до 39 млн. В 1762 году, по оценкам В.О. Ключевского, государственных доходов насчитывалось 16 млн рублей, в 1796-68,5 млн.

Купеческий класс к концу царствования Екатерины составлял 240 тыс. человек. Он был выведен из разряда податных сословий с освобождением от внесения в по- душный оклад, который был заменен однопроцентным налогом на капитал, причем размер капитала объявлялся самим купцом «по совести». Импульс экономических преобразований Екатерины II был настолько силен, что двадцать лет после ее кончины в России не реализовывалось радикальных хозяйственных реформ, за исключением принятых мер мобилизационного характера во время войны с Наполеоном[3,cc252-253].

Эти базовые институциональные и социетальные уроки делают интересным целый ряд вопросов, тесно связанных с современностью.

Принципиальное изменение финансово-экономических и военно-политических отношений России с Западом, необходимость пересмотра парадигм технологического, экономического и социального развития в связи с экономическими санкциями проблематизируют исследования не только ресурсов, целей, механизмов трансформации политико-экономической системы современной России в контексте ее геополитических интересов и актуализации национального плана развития, но и исторического декодирования позиций такого драйвера реформ, как предпринимательство.

На протяжении многих лет феномен отечественного предпринимательства и политика по отношению к нему государства российского занимает прочное место в историческом контексте политико-экономического дискурса. При этом, как правило, вне поля зрения ученых остается изучение границ некоего социокультурного коридора, в котором в России возможно развитие предпринимательства.

Среди современных ученых существуют разные подходы к трактовке проблем эволюции взаимоотношений российского предпринимательства и государства. При этом надо иметь в виду, что многие аналитические инструментарии отягощены идеологическими оценочными суждениями, механизм отбора теоретического и эмпирического материала имеет очевидный ценностно-политический оттенок несовместимости различных политико-экономических идеологий. Те или иные модные политические дискурсы способствуют формированию теоретических конструкций, зачастую пытающихся представить желаемое состояние правил взаимодействия политических и экономических институтов за реальное положение дел. Разные этапы этого 
взаимодействия имели свою историческую специфику, но всегда достаточно четко маркировались сложившиеся в России различия между разными стратами предпринимательства - производительным, непроизводительным и деструктивным. Автор этой классификации - У. Баумоль, используя примеры из истории разных экономических эпох и регионов, показал, что «предпринимательство всегда с нами и всегда играет [в жизни общества] весьма значительную роль. Но в одних случаях предпринимательство развивается в тех сферах деятельности, где приносит пользу, а в других - там, где наносит ущерб экономике, паразитируя на ней»[4,cс.61-84]. Как действует предприниматель в данное время и в данном месте, зависит прежде всего от правил игры - производительное предпринимательство, развивается за счет генерирования инновационной ренты, непроизводительное - получает прибыль за счет перераспределения государственной казны и активов , а деструктивное - за счет использования высокими чинами своих возможностей для принуждения предпринимателей к выплате политической ренты. В Древнем Риме, пишет Баумоль, «где хорошо прослеживается неограниченное стремление к обогащению, для лиц высокого общественного положения было три основных источника дохода: землевладение, ростовщичество и «политические платежи»». Таким образом, источниками нелегитимных доходов и непроизводительного, и деструктивного предпринимательства является рента от корыстного использования публичных благ- « все они были политическими и паразитическими, путями завоеваний, грабежей и ростовщичества; труд - даже труд предпринимателя - не был одним из них». У. Баумоль обращал внимание на то, что предпринимательское использование правовой системы для рентоискательства («непроизводительная для общества деятельность на «политическом рынке» с целью создания привилегий для избранных») имеет длинную историю в разных странах, демонстрируя иногда довольно значительные «приливы» и «отливы». Баумоль подчеркивает: «история показывает, что изменения правил хозяйственной деятельности можно осуществлять быстро и основательно».

В истории России таким примером «быстрого и основательного» изменения правил игры для российских предпринимателей, особой вехой в истории отечественного предпринимательства стала либеральная политика Екатерины II в 1760-1790-е годы. Историк Сергей Платонов обоснованно полагал: «Экономическая политика Екатерины отличалась существенно от политики предыдущих царствований. С Петра Великого у нас установилась над торговлей и промышленностью система строгого правительственного надзора, и деятельность торгово-промышленного класса была стеснена регламентацией. Екатерина сняла эти стеснения, уничтожила самые органы контроля - Берг-и Мануфактурколлегию - и стала держаться в отношении торговли и промышленности известного принципа «laissez - faire, laissez - passer» - государственного невмешательства и свободы рыночных сил. Этот принцип в ее время был уже высказан и английскими, и французскими экономистами и сочувственно принимался корифеями французской философии. Екатерина усвоила его: она содействовала развитию промышленности и торговли, но она не направляла это развитие в ту или другую сторону»[5,c. 633].

Надо иметь в виду, что многие аналитические инструментарии исследования историко-культурных аспектов отношений предпринимательства и государства в России отягощены идеологическими оценочными суждениями, механизм отбора теоретического и эмпирического материала имеет очевидный ценностно-политический оттенок несовместимости различных политико-экономических идеологий. Те или иные модные политические дискурсы способствуют формированию теоретических конструкций, зачастую пытающихся представить желаемое состояние правил взаимодействия политических и экономических институтов за реальное положение дел. С. Н. Булгаков писал, что «всякая хозяйственная эпоха имеет свой дух, и в свою очередь, является порождением этого духа, каждая экономическая эпоха имеет свой особый тип “экономического человека”, порождаемый духом хозяйства»[6,c.233]. Не случайно, автор в знаменитого документа 1946 года «Длинной телеграммы» - американский дипломат Джордж Кеннан , которого считают архитектором холодной войны и автором плана «сдерживания» России, в статье 1951 года уделял оценкам пути, по которому движется отечественное предпринимательство, особое место. Он полагал, что « Россия едва ли была знакома с частной инициативой, в том ее виде, к которому мы привыкли в Америке. Даже в дореволюционные времена русское правительство всегда держало в своих руках целый ряд экономических отраслей...Частный русский капитал играл более важную роль в области товарообмена, чем в области промышленного производства. Русские предприниматели создавали главным образом торговлю, а не промышленность. К тому же торговопромышленная деятельность не считалась в России таким почетным занятием, как на Западе. Существовало традиционное, коренное русское, купеческое сословие, 
DOI: $10.7256 / 1811-9018.2015 .7 .15439$

При цитировании этой статьи сноска на доі обязательна

\section{Право и политика 7 (187) 2015}

но оно не отличалось ни широтой кругозора, ни сознанием своей социальной роли и потому не вызывало к себе особого уважения..... В русском языке не было слова, соответствующего нашему понятию businessman; в нем было только слово купец, и этот термин далеко не всегда имел лестное значение. Русский промышленник стоял на виду у всех, во плоти, и часто напоминал своей тучностью, а иногда (не всегда, конечно) и своей грубой вульгарностью, капиталиста, изображаемого карикатуристами эпохи раннего коммунизма»[7,cc.123-125]. Дэвид Ландес в своей знаменитой статье характеризовал такой тип культуры, как “враждебный к предпринимательству”.Доказывая положение о том, что в истории экономики почти все объясняется культурой, Ландес пишет:«Здесь показателен опыт России, где семьдесят пять лет антирыночной и антибуржуазной пропаганды насадили крайне враждебное отношение к частной инициативе. Даже сейчас, когда коммунистический режим рухнул, люди опасаются неопределенностей рынка и уповают на скуку государственного попечения. Они предпочитают равенство в бедности, присущее земледельческим культурам по всему миру. В одной русской сказке говорится о том, как мужик Иван завидовал другому мужику, Борису, поскольку у того была коза. Однажды появляется волшебница и предлагает Ивану исполнить любое его желание. И чего же, как вы думаете, он желает? Чтобы у Бориса коза сдохла. К счастью, не все русские таковы»[8,с.40]. Действительно, Россия в разные времена вызывала у западных исследователей изумление быстро нажитыми состояниями, бурным развитием новых социальных общностей, необыкновенно быстрыми и вовсе неожиданными возвышениями, когда «в среду старинной русской знати вступали беспрестанно люди с именами прежде неизвестными. Они получали почетные титулы, высокие чины, важные придворные должности и значительное, а иногда даже громадное богатство, и вдобавок к этому они роднились с известными фамилиями»[9,с.178]. Не случайно, известный исследователь России, отнюдь не относящийся к не в превосходных степенях, Ричард Пайпс, настойчиво опровегал тезис об отсутствии у россиян предпринимательской жилки: «жители России всегда отличались незаурядной склонностью к торговле и промышленной деятельности, да и природная скудость почвы понуждала их к предпринимательству. Не следует идти на поводу у статистических данных, показывающих, что при старом режиме почти все население Европейской России состояло из дворян и крестьян... В действительности гораздо большая часть населения России всегда занималась торговлей и про- мышленностью, что можно было заключить из данных официальных переписей»[10,сс.252-253].

В данной статье нас будут интересовать прежде всего историко-культурный контекст соотношения формальных и неформальных правил для развития российского предпринимательства.

Свой анализ уместно начать с обращения к наследию М. Вебера для раскрытия генезиса в России “патримониально-политического капитализма”. Он определял его сущность как ориентацию «на возможность немедленной премиальной добычи получаемую за услугу политическим или околополитическим субъектам,... на извлечение постоянного дохода с применением силы на основе политического господства»[11]. Вебер поставил вопрос о двух типах капитализма, выделяя специфические особенности, существенно отличающие современное рациональное предпринимательство от капитализма « ростовщиков, военных поставщиков, откупщиков должностей и налогов, крупных торговых предпринимателей и финансовых магнатов».В понимании Вебера-это предпринимательство авантюристическое, получающее от государства на откуп должности и налоги, финансирующее «вождей партии», занимающиеся торговыми и кредитными операциями, имеющее иррационально-спекулятивный характер и ориентированное на насильственную добычу- либо за счет войны, либо за счет фискальной эксплуатации государственных подданных[12,с.11,61]. Хорошо знакомый с работами М. Вебера, С.Н. Булгаков говорил о необходимости изучения культурного фактора в экономике: «Исследования из истории русской промышленности, в связи с духовными биографиями и всей бытовой обстановкой русских пионеров-предпринимателей, раскрыли бы религиозно-этические основы психологии русской промышленности»[13,с.361].

В самой общей форме наш основной тезис заключается в том, что рассмотрение особенностей «генетической» связи российской системы « предпринимательство - власть » с предшествующими состояниями, постижение собственной современности в ее историческом измерении, наполнено историческими и современными иллюстрациями тезиса В.Г.Белинского. 165 лет назад он в письме Н.В.Гоголю характеризовал Россию как страну «где, наконец, нет не только никаких гарантий для личности, чести и собственности, но нет даже и полицейского порядка, а есть только огромные корпорации разных служебных воров и грабителей»[14]. Посмотрим теперь, как в свете этого тезиса выглядит проблема исторического генезиса российского предпринимательства, сфокусировав свои наблюдения 
на следующих особенностях. предпринимательство в России было изначально зависимо от государства. Предприниматель зачастую выступал как проситель, и возможность заниматься предпринимательством зависела от государственных чиновников. Эта структура отношений могла упрощаться или усложняться, содержательное властное влияние на предпринимательство - комбинироваться в разной пропорции и в разной структурной аранжировке , практики «воспитания бизнеса» - быть более (менее) разнообразными или рутинизированными. Но основные параметры модели, которую В. О. Ключевский назвал «казенно-парниковым воспитанием промышленности», оставались неизменными. Ее суть великий русский историк усматривал в сочетании государственного лелеяния льготами частных любимых компаний и постепенного удаления их от западноевропейских образцов свободного предпринимательства, переделки «на московский лад»[15,c.823].

Русский философ Иван Ильин, отвечая на вопросы: «Должно ли государство беречь духовную самостоятельность и творческую самодеятельность граждан - и в культуре, и в политике, и в хозяйстве - или же.... должно стремиться к изъятию и огосударствлению частной собственности, принадлежащей отдельным гражданам, их семьям и их свободным объединениям (корпорациям)? Возможны ли свобода и творческая инициатива без частной собственности?», утверждал, что бюрократически ведомое безразличными чиновниками хозяйство хозяйствование общественно и государственно вредно, а господство частной собственности, «должно быть прочно обеспеченным, т. е. оно должно быть оговорено в законах, ограждено правосознанием сограждан, полицией и судом, и не подвергаться постоянным угрозам отчуждения или тем более бесплатного отчуждения со стороны политических партий или государственной власти. Частный собственник должен быть уверен в своем господстве над своими вещами, т. е. в законности этого господства, в его признанности, почтенности и жизненной целесообразности; он должен быть спокоен за него, за его бесспорность и длительность, за то, что имущество его не будет подвергаться ни нападению, ни расхищению, ни поджогу, ни экспроприации; он должен спокойно помышлять о судьбе своих вещей замыслом долгого и творческого дыхания, предусматривая частные интересы своих детей и внуков»[16,с. 278].

Екатерина II писала, что в 1762 г., при вступлении на престол, она нашла империю таковой: «Армия была еще за границей и не получала восьмой месяц жалованья. На Штатсъ-конторе было семнадцать миллионов долгу.
Ни единый человек в государстве не знал, сколько в казне было дохода. Повсюду народ приносил жалобу на лихоимство, взятку, притеснение и неправосудие, все ветви коммерции почти были отданы частным людям на откуп, флот был в упущении, армия в расстройстве , крепости развалились»[17,с.641]. В.О. Ключевский пишет: «Высший контролер государственного хозяйства - Сенат не мог установить точной бюджетной росписи. По воцарении Екатерины он подал ей реестр доходов, по которому их значилось 16 млн. Екатерина велела пересчитать доходы, и счетная комиссия насчитала их 28 млн; 12 млн Сенату были неведомы. Зато в расточении государственных имуществ и доходов он показал большую энергию. Все таможни он отдал на откуп за 2 млн, а когда они взяты были Екатериной в казенное управление, одна петербургская таможня давала более 3 млн дохода. Казенные заводы в конце царствования Елизаветы самовольно были переданы Сенатом в частное владение первейшим царедворцам: Шуваловым, Воронцовым, Чернышевым и т.п., да им же роздано на ведение дела до 3 млн руб. Ссуду заводчики промотали в столице, заводским крестьянам платили за работу плохо или вовсе не платили, и они взбунтовались в числе 49 тыс.; пришлось посылать усмирительные команды с пушками, а заводы возвратить за долги в казну. Всего в виде займов и другими способами расхватали до 4 млн деньгами и более 7 млн землями и рудниками и приходили в негодование на несправедливость казны, когда она требовала возврата денег, давно растраченных. Доверия к правительству не было никакого, но все привыкли думать, что никакого другого распоряжения от него и исходить не могло, кроме вредного к общему благу. Значит, государство утратило свой смысл в народном мнении и даже превратилось в какой-то заговор против народа»[15,с.1023].

Программными в сфере экономической политики принято считать написанные ей в 1767 г. «Рассуждение о мануфактурах» и «Рассуждение по здравому понятию». Основной посыл этих документов: «Вольность есть право все то делать, что законы дозволяют», «Политическая свобода в отношении к гражданину состоит в безопасности под защитой закона, или, по крайней мере, в мысли о такой безопасности, которая гражданину позволяет не бояться своего соседа»[17,с.623]. Екатерина полагала великим злом промышленные привилегии и монополии-«не должно никому мешать честным образом доставать свой хлеб, и что менее правительства мешаются в состояние людей честных, тем полезнее для сих последних», «чем больше над крестьянином притеснителей, тем хуже для 
DOI: $10.7256 / 1811-9018.2015 .7 .15439$

При цитировании этой статьи сноска на доі обязательна

\section{Право и политика 7 (187) 2015}

него и для земледелия..Великий двигатель земледелиясвобода и собственность»[17,с.629]. В «Рассуждения о мануфактурах» Екатерина II провозгласила принцип -«не запрещать и не принуждать», занятие ремеслами становятся доступными для каждого. Принципиальным требованием императрицы было- «Не мешайте ему и не сделайте много учреждений»[18].

Екатерина пишет: « Нету ничего опаснее, как захотеть на все сделать регламенты», лишь потребности населения должны быть решающим фактором развития экономики. «Если б в чем не нашли барыша, то бы то не делали», «сами заведут ( предприятия-авт.), лишь не мешайте им». Общим лозунгом императрицы ряд исследователей справедливо полагает постоянно встречающееся фразы- «Не запрещать и не принуждать», «Мы лучше ничего не делаем, как что делаем вольно, непринужденно», «кто достает честным образом свой хлеб, - сами разберутся, что кому делать», «Если бы на все просить дозволение, то бы не было права». Либерализация торгово-промышленной деятельности тесно связывалась с ликвидацией монополий. В указах от 31 июля 1762 г., от 18 февраля 1763 г. четко обозначен принцип свободы предпринимательства- «всем позволить невозбранно», причем отвергалось право какихлибо кампаний на монополию в той или иной сфере или регионе. Любопытен ответ Екатерины на один из предложенных Г.А. Потемкиным проектов: «Прочтя сей проект, я нашла, [что] оной составлен по правилам всех монополистов, то есть - захватить все в свои руки, несмотря на разорение вещей и людей, из того последуемое. В начале моего царствования я нашла, [что] вся Россия по частям роздана подобным кампаниям. И хотя я девятнадцать лет стараюсь сей корень истребить, но вижу, что еще не успеваю, ибо отрыжки (авось либо удастся) сим проектом оказываются»[19,с.148].

Показателен в этом отношении исторический пример Петра Ивановича Шувалова, двоюродного брата фаворита императрицы Елизаветы Петровны (17411761). И.И.Шувалова и родного брата всесильного главы Тайной канцелярии А.И.Шувалова. В 1748 г. «он взял на откуп сальный промысел, затем прибрал к рукам китоловный, тюлений и другие промыслы на севере. Став крупнейшим «монополистом», он подорвал основу мелкого предпринимательства и промыслов на Севере и Каспии»[20,c.189].

Современные российские исследователи отмечают: «Существование уже в XVIII в. таких явлений, как “семья" (в широком смысле слова) и близкие к этой “семье”“"олигархи” (или, как говорили тогда, “временщики”, а то и просто, имея в виду Петра и Александра
Шуваловых, “братья-разбойники”). Но главное - глубоко антирыночный характер этой псевдоприватизации, поскольку, как мы видели, существование "крупного бизнеса", подобного шуваловскому (основанного на разворовывании государственной казны, коррупции чиновничьего аппарата, близости к любовникам, фрейлинам и чесальщицам ног императрицы), препятствовало развитию подлинного предпринимательства» $[21, \mathrm{c.26}]$.

Екатерина, принимая либеральные принципы, в Манифесте от 28 июня 1782 года «О распространении права собственности владельцев на все произведения земли на поверхности и в недрах ее содержащихся» сразу подчеркивает: «С первых дней царствования Нашего постановили Мы себе непреложенным правилом, чтоб во всех промыслах и упражнениях, свойственных государству нашему,... изъять из среди всякое принуждение; а на против того оживотворить и умножить оныя свободою и разными одобрениями»[22,c.613]. Намерение даровать всем полную свободу предпринимательства, «как сущее народное облегчение», не могло быть приведено в исполнение в начале царствования в силу состояния управления в губерниях и областях. Однако теперь, когда даже самые отдаленные страны Империи управляются должным образом, а «опыты открыли Нам многия познания в истине правил Нами исповедуемых, Нас утверждающия», Екатерина не только расширяет права собственности землевладельцев и на земные недра и дарует им полную свободу в добывании полезных руд, которые там содержатся, разрешает их частную переработку, но и допускает передачу прав другим лицам на их добычу, обработку и создание для этого заводов на « основании законов для общего производства полезного деда». Примечательно, как в статье 5 изящно решается проблема разработки природных ресурсов на государственных землях. Кто это должен осуществлять? Екатерина подчеркивает, что главным критерием здесь является принцип : «каким образом выгоднее получать руды для казны потребные, наблюдая тут пользу Нашу и облегчение народное». В Манифесте формулируются и принципы свободы внешней торговли с установление особых пошлин и тарифов.

В статьях 13-16 того же самого закона, по сути, сформулированы принципы взаимоотношений между предпринимательством и государством. Во- первых, запрещается требовать для строительства заводов « более земли, что он имеет или что отведено по договору». Во-вторых, запрещается требовать отвода казенных лесов - «долженствует пользоваться своими собственными или покупая их у других». В-третьих, все промыслы должны быть вольными и непринужден- 
ными. В-четвертых, Екатерина особо подчеркивает, что со стороны государственных учреждений под особым контролем, «под опасением гнева Нашего за небрежение и попущения», должно быть недопущение монополии-«ни единый из промыслов ни кому в монополию присвоен не был». кроме того, воспрещалось казенным учреждениям вмешиваться в «управление и распоряжение заводов и промыслов частных людей».

Таким образом, Екатерина ставила задачу ограничить роль государства российского рамками регулирования условий ведения предпринимательской деятельности. Но главным всегда являлось регулирования доступа к дефицитным ресурсам. Системная задача превращения территориального и социального пространства в пространство власти, контролируемое и управляемое, требовало обеспечения средств для реагирования на угрожающие российской государственности события. Считая, что «торг-дело вольное», она стала уничтожать многие казенные монополии, расширять правовые основы формирования частного предпринимательства. Однако, несмотря на огромное значение екатерининских преобразований, основной доминантой хозяйственной стратегии и критерием успеха предпринимательства в России осталось поглощение чужой собственности, а не ее создание и эффективное управление. Для успешного ведения своего дела предприниматель в России должен в первую очередь уметь ладить с властью, налаживать контакты с чиновниками, а вовсе не разбираться в стратегическом маркетинге или менеджменте. На эту особенность указывал и С.Ю.Витте, отмечавший, что предпринимательство в стране всегда находилось «в значительной зависимости от многочисленных местных властей, начиная от урядника и восходя до генерал-губернатора, и эти местные влияния могут быть полезны и благотворны только тогда, когда все органы власти проникнуться убеждением, что развитие промышленности есть благо с государственной и народно-хозяйственной точки зрения»[23,с.139].

Роль государства российского всегда выходила за рамки регулирования условий ведения предпринимательской деятельности, главным всегда являлось регулирования доступа к дефицитным ресурсам. Системная задача превращения территориального и социального пространства в пространство власти, контролируемое и управляемое, требовала обеспечения средств для реагирования на угрожающие российской государственности события [24,25]. Отсюда - специфическая форма, определяемая В.П.Булдаковым как «государство-склад» [26, с. 355].

Этот концепт можно рассматривать как способ наблюдения и описания российского общества, как ресурсно-распределительную «линзу» российской политики, характеризующую неспособность населения самостоятельно распоряжаться ресурсами и отношение предпринимателей к власти не только как к кормушке, но и как к «большому Хозяину». Это единство власти и права Хозяина формирует некую «недособственность» даже у крупнейших российских предпринимателей. В. Розанов писал: «В России вся собственность выросла из «выпросил» или «подарил», или кого-нибудь «обобрал». Труда в собственности очень мало. И от этого она не крепка и не уважается» [27] Известный российский журналист Владимир Соловьев по этому поводу удачно заметил: «Необходимо четко понимать, что стоимость бизнеса в России равна тому, сколько стоит этот бизнес отобрать: все списки «Форбса» - для идиотов»[28, c. 168]. Не случайно ни одна из известных купеческих династий XVIII века не сохранила своего положения до начала XX века [29, с. 42].

\section{Библиография:}

1. Панарин А. Цивилизационный процесс в России: опыт поражения и уроки на завтра.//Знамя,1992,№7

2. Полное собрание законов Российской Империи. Том 20, СПб., 1830.

3. Никонов В.А.Российская матрица. М.: Русское слово,2014.

4. Баумоль У. Предпринимательство: производительное, непроизводительное деструктивное// Российский журнал менеджмента, 2013, Т.11.

5. Платонов С. Ф. Курс лекций по русской истории. М.: Высшая школа, 1993.

6. Булгаков С. Н. Философия хозяйства. Соч. в 2-х тт. Т.1. М.: Наука,1993.

7. Социокультурные особенности российской модернизации: материалы круглого стола. М.: Экон-Информ, 2009.

8. Ландес Д. Культура объясняет почти все.// Культура имеет значение. Каким образом ценности способствуют общественному прогрессу. Под ред. Л. Харрисона и С. Хантингтона. М.: Московская школа политических исследований, 2002.

9. Карнович Е.П. Замечательные богатства частных лиц в России. СПб., 1885.

10. Пайпс Р. Россия при старом режиме. М.: «Захаров», 2012.

11. Вебер М. Типология капитализма./Кустарев А. Капитализм в XXI веке: минус протестантская этика плюс конфуцианство// Неприкосновенный запас. 2011, № 5. [Электронный ресурc] URL: http://www.nlobooks.ru/node/1045 (дата обращения: 19.05.2015). 
DOI: $10.7256 / 1811-9018.2015 .7 .15439$

При цитировании этой статьи сноска на dоі обязательна

\section{Право и политика 7 (187) $\bullet 2015$}

12. Вебер М. Избранное. Протестанская этика и дух капитализма. М.; СПб: Центр гуманитарных инициатив, 2013.

13. Булгаков С. Н. Народное хозяйство и религиозная личность // Булгаков С. Н. Избранные статьи. Т. 2. М.: Наука, 1993.

14. Белинский В.Г.Письмо к Н.В. Гоголю от 15 июля 1847 г. [Электронный ресурc] // Русская литература и фольклор. URL: http://feb-web.ru/feb/gogol/texts/ps0/ps8/ps8-5002.htm (дата обращения: 03.05.2015).

15. Ключевский В.О. Курс русской истории. М. :Альфа-Книга, 2011.

16. Ильин И.А. Путь к очевидности. М.: Республика, 1993.

17. Записки императрицы Екатерины Второй. Санкт-Петербург: типограф. А. С. Суворина, 1907.

18. Леонтович В.В.. История либерализма в России. М.: Русский путь, 1995.

19. Екатерина Вторая и Г. А. Потемкин. Личная переписка (1769-1791). М.: Наука, 1997.

20. Анисимов Е.В. Россия в середине XVIII века. Борьба за наследие Петра. М.: Мысль, 1986.

21. Лукин А.В., Лукин П.В.Экономическая политика в постсоветской России и российская история.//Полис, 2011 , №4.

22. Полное собрание законов Российской Империи, том 21. СПб., 1830.

23. Витте С.Ю. О положении нашей промышленности. Всеподданнейший доклад министра финансов.// Историк-марксист, 1932, № 2/3.

24. Осипов И.Д. Власть и предпринимательство в России: историко-культурный аспект взаимоотношений // GR-связи с государством. Теория, практика и механизмы взаимодействия бизнеса и гражданского общества с государством. М.: РОССПЭН, 2012.

25. Алейников А.В. Становление бизнеса как социально-политического института современной России. Монография. СанктПетербург : Изд. дом Санкт-Петербургского гос. ун-та,2008.

26. Труды по россиеведению. М.:РАН. ИНИОН, 2009

27. Розанов В.В. Уединенное. [Электронный ресурс] // Библиотека русской религиозной философской и художественной литературы «Вехи». URL: http://www.vehi.net/rozanov/ (дата обращения: 04.05.2015).

28. Соловьев В.Р. Путин. Путеводитель для неравнодушных. М.: Эксмо, 2008

29. Петров Ю. Предприниматели и российское общество в начале ХХ века // Свободная мысль. 1992. № 17.

\section{References (transliterated):}

1. Panarin A. Tsivilizatsionnyi protsess v Rossii: opyt porazheniya i uroki na zavtra.//Znamya,1992,№7

2. Nikonov V.A.Rossiiskaya matritsa. M.: Russkoe slovo,2014.

3. Baumol' U. Predprinimatel'stvo: proizvoditel'noe, neproizvoditel'noe destruktivnoe// Rossiiskii zhurnal menedzhmenta, 2013 , T.11.

4. Platonov S. F. Kurs lektsii po russkoi istorii. M.: Vysshaya shkola, 1993.

5. Bulgakov S. N. Filosofiya khozyaistva. Soch. v 2-kh tt. T.1. M.: Nauka,1993.

6. Landes D. Kul'tura ob"yasnyaet pochti vse.// Kul'tura imeet znachenie. Kakim obrazom tsennosti sposobstvuyut obshchestvennomu progressu. Pod red. L. Kharrisona i S. Khantingtona. M.: Moskovskaya shkola politicheskikh issledovanii, 2002.

7. Karnovich E.P. Zamechatel'nye bogatstva chastnykh lits v Rossii. SPb., 1885.

8. 10. Paips R. Rossiya pri starom rezhime. M.: «Zakharov», 2012.

9. Veber M. Tipologiya kapitalizma.//Kustarev A. Kapitalizm v XXI veke: minus protestantskaya etika plyus konfutsianstvo// Neprikosnovennyi zapas. 2011, № 5. [Elektronnyi resurs] URL: http://www.nlobooks.ru/node/1045 (data obrashcheniya: 19.05.2015).

10. Veber M. Izbrannoe. Protestanskaya etika i dukh kapitalizma. M.; CPb: Tsentr gumanitarnykh initsiativ, 2013.

11. Bulgakov S. N. Narodnoe khozyaistvo i religioznaya lichnost'// Bulgakov S. N. Izbrannye stat'i. T. 2 . M.: Nauka, 1993.

12. Belinskii V.G.Pis'mo k N.V. Gogolyu ot 15 iyulya 1847 g. [Elektronnyi resurs] // Russkaya literatura i fol'klor. URL: http://febweb.ru/feb/gogol/texts/ps0/ps8/ps8-5002.htm (data obrashcheniya: 03.05.2015).

13. Klyuchevskii V.O. Kurs russkoi istorii. M. :Al'fa-Kniga, 2011.

14. Il'in I.A. Put' k ochevidnosti. M.: Respublika, 1993.

15. Zapiski imperatritsy Ekateriny Vtoroi. Sankt-Peterburg: tipograf. A. S. Suvorina, 1907.

16. Leontovich V.V.. Istoriya liberalizma v Rossii. M.: Russkii put', 1995.

17. Ekaterina Vtoraya i G. A. Potemkin. Lichnaya perepiska (1769-1791). M.: Nauka, 1997.

18. Anisimov E.V. Rossiya v seredine XVIII veka. Bor'ba za nasledie Petra. M.: Mysl', 1986.

19. Lukin A.V., Lukin P.V.Ekonomicheskaya politika v postsovetskoi Rossii i rossiiskaya istoriya.//Polis, 2011 , №4.

20. Vitte S.Yu. O polozhenii nashei promyshlennosti. Vsepoddanneishii doklad ministra finansov.// Istorik-marksist, 1932 , № 2/3.

21. Osipov I.D. Vlast' i predprinimatel'stvo v Rossii: istoriko-kul'turnyi aspekt vzaimootnoshenii // GR-svyazi s gosudarstvom. Teoriya, praktika i mekhanizmy vzaimodeistviya biznesa i grazhdanskogo obshchestva s gosudarstvom. M.: ROSSPEN, 2012.

22. Aleinikov A.V. Stanovlenie biznesa kak sotsial'no-politicheskogo instituta sovremennoi Rossii. Monografiya. Sankt-Peterburg : Izd. dom Sankt-Peterburgskogo gos. un-ta,2008.

23. Rozanov V.V. Uedinennoe. [Elektronnyi resurs] // Biblioteka russkoi religioznoi filosofskoi i khudozhestvennoi literatury «Vekhi». URL: http://www.vehi.net/rozanov/ (data obrashcheniya: 04.05.2015).

24. Solov'ev V.R. Putin. Putevoditel' dlya neravnodushnykh. M.: Eksmo, 2008

25. Petrov Yu. Predprinimateli i rossiiskoe obshchestvo v nachale XX veka // Svobodnaya mysl’. 1992. № 17. 